\title{
Indicador da qualidade da água através de análise fatorial: um estudo de caso na zona portuária de Belém, Amazônia, Brasil
}

A zona portuária de Belém, situada no estuário Guajarino, abriga os portos de Belém, Terminal Petroquímico de Miramar e Porto de Outeiro. Neste sentido, este estudo buscou criar indicadores de qualidade da água, através da análise fatorial que reflitam as peculiaridades e a dinâmica da zona portuária de Belém. Foram feitas amostragens mensais de água ao longo dos anos de 2014 e 2016, em toda zona portuária, englobando os três. Os resultados foram submetidos a análise fatorial (AF) para criação do Indicador de Avaliação Padronizado (IAP), que classificou a qualidade das águas amostradas nas faixas péssima, ruim, regular, boa e ótima. Os resultados mostraram que $46,03 \%$ e $42,85 \%$ das amostras do porto de Belém ficaram classificadas como péssimas e ruins, respectivamente. 0 terminal de Miramar apresentou classificação péssima para $46,98 \%$ das amostras, e o porto de Belém concentrou $45,98 \%$ dessas amostras analisadas na faixa de qualidade ruim; por fim, o Porto de Outeiro também mostrou uma qualidade péssima para 52,58\% das amostras. A AF possibilitou uma visão integrada dos dados, mostrando como os efeitos das atividades desenvolvidas ao longo da zona portuária de Belém influenciam a qualidade da água.

Palavras-chave: Indicadores de Avaliação; Estuário; Baia do Guajará; Métodos Quantitativos.

\section{Water quality indicator through factor analysis: a case study in the port area of Belém, Amazonia, Brazil}

In the port zone of Belém, located at Guajarino estuary, shelters ports of Belém, Miramar Petrochemical Terminal an Outeiro Port. In this regard, this study searched create indicators of water quality, through the factorial analysis that mirror the peculiarities and the dynamics of the port zone of Belém. Were made monthly samples of water along the years of 2014 and 2015, in the entire port zone, encompassing the three ones. The results were submitted to factorial analysis (FA) for the creation of Standardized Evaluation Indicator (SEI), that classified the water quality sampled in the lousy, bad, regular, good and excellent. The results showed that $46,03 \%$ and $42,85 \%$ of the samples from the port zone of Belém were classified as lousy and bad, respectively. The Miramar Terminal presents classification lousy for $46,98 \%$ of the samples, and the port zone of Belém concentrated $45,98 \%$ of these samples analyzed in the range of bad quality; at last, the Outeiro Port also showed a lousy quality for $52,58 \%$ of the samples. The AF made possible an integrated vision of the data, showing how the effects from the activities developed along the port zone of Belém have an influence in water quality.

Keywords: Evaluation Indicators; Estuary; Guajará Bay; Quantitative Methods.

Topic: Uso de Recursos Naturais

Reviewed anonymously in the process of blind peer
Received: 06/03/2021

Approved: 22/03/2021
Eder Silva de Oliveira (10

Universidade do Estado do Pará, Brasil http://orcid.org/0000-0002-2560-2214 ederso@uepa.br

Diego Nascimento Santos (iD Universidade Federal Rural da Amazônia, Brasil http://orcid.org/0000-0002-7256-5823 nascimentodiego14@gmail.com

Gilmara Maureline Teles da Silva de Oliveira (id Universidade Federal Rural da Amazônia, Brasil http://orcid.org/0000-0001-6715-5945 gilmarateles.eng@gmail.com
Mario Lopes Silva Junior (iD

Universidade Federal Rural da Amazônia, Brasil http://orcid.org/0000-0001-9772-1290 mario.silva@ufra.edu.br

Cristiane da Costa Gonçalves de Andrade (iD) Universidade Federal do Pará, Brasil http://orcid.org/0000-0002-8119-7110 candrade@cdp.com.br

Washington Aleksander Savaris dos Santos (iD) Universidade do Estado do Pará, Brasil http://orcid.org/0000-0002-5964-2230 aleksandersantos05@gmail.com
Hebe Morganne Campos Ribeiro (D) Universidade do Estado do Pará, Brasil http://orcid.org/0000-0001-7154-9947 hebemcr@gmail.com
Referencing this:

OLIVEIRA, E. S.; SANTOS, D. N.; OLIVEIRA, G. M. T. S.; SILVA JUNIOR, M. L.; ANDRADE, C. C. G.; SANTOS, W. A. S.; RIBEIRO, H. M. C.. Indicador da qualidade da água através de análise fatorial: um estudo de caso na zona portuária de Belém, Amazônia, Brasil. Revista Ibero Americana de Ciências Ambientais, v.12, n.3, p.640-650, 2021. DOI: http://doi.org/10.6008/CBPC2179-6858.2021.003.0051 


\section{INTRODUÇÃO}

A região amazônica possui abundância em recursos hídricos, porém, a qualidade desse recurso é fortemente afetada pela grande variedade de usos desenvolvidos em suas bacias hidrográficas. Dentre estes usos, a navegação sempre foi o principal meio de transporte da população e fluxo de produtos das atividades econômicas (CASTRO, 2004; RAMOS, 2004).

A cidade de Belém, uma das metrópoles amazônicas, localizada no estuário Guajarino, representa o maior adensamento demográfico da região Amazônica e os corpos hídricos que circundam a cidade recebem os efluentes de $30 \mathrm{~km}$ de drenagens naturais, transformadas em canais municipais de esgoto sem tratamento, que transportam poluentes e contaminantes de toda a zona urbana. Além disso, a cidade tem um alto tráfego de navios e possui grandes zonas portuárias, compostas também de pequenos portos e trapiches de madeira que abrigam inúmeros trabalhadores que chegam de localidades vizinhas, ilhas ou vilarejos localizados às margens de rios e furos, em suas proximidades (CASTRO, 2004; CORREIA et al., 2019).

A zona portuária de Belém fica na Baia de Guajará que recebe contribuição hídrica e sedimentar dos rios Guamá, Acará e Mojú, dois importantes sistemas fluviais. Essa zona tem importância significativa na economia da região através do escoamento da produção do estado e armazenamento de produtos de diversas tipologias (GREGÓRIO, 2009; OLIVEIRA, et al., 2015).

De acordo com as informações da Companhia Docas do Pará - Portal CDP, o Porto de Belém movimenta em média, cerca de 90.000 toneladas de cargas mensalmente, entre granel sólido, granel líquido, conteres e cargas em geral. A Companhia Docas do Pará - CDP, responsável pela administração de 8 unidades portuárias, entre elas estão o Porto de Belém, Terminal Petroquímico de Miramar, Terminal Portuário de Outeiro, mantém o monitoramento mensal do corpo hídrico nas áreas de influência dessas unidades portuárias.

Toda essa dinâmica portuária implica na intensificação da poluição do corpo hídrico, haja vista que os estuários recebem todos os materiais provenientes de rios contribuintes da bacia hidrográfica, além da ocupação de suas margens por indústrias que se instalam visando à facilidade de transporte oferecida pelo corpo hídrico. Dessa forma, os efluentes domésticos e industriais despejados em rios ou diretamente na zona de estuário, acabam comprometendo a qualidade do recurso hídrico (TUNDISI et al., 2008).

A água precisa ter um padrão de qualidade que esteja acima de suspeitas. Desse modo, qualquer ação desenvolvida para verificar a qualidade da água produz um elevado número de informações que precisam ser analisadas e sintetizadas a fim de que sejam melhor entendidas, sem perder, contudo, seu grau de significância. Este tipo de informação é fundamental na gestão de recursos hídricos, norteando ações de avaliação, controle e monitoramento dos mesmos.

Nesse sentido, a avaliação e o gerenciamento da qualidade da água são essenciais para monitorar os impactos da ocupação de bacia hidrográfica ao longo do tempo. Para tal, diversos são os parâmetros de monitoramento da qualidade da água, o que por vezes dificulta a análise integrada do fenômeno, sobretudo quando se trata de monitoramento de vários anos (FERREIRA et al., 2015). 
Contudo, métodos de análise estatística multivariada como análise fatorial/análise de componentes principais pode condensar as informações e transmiti-la de maneira mais compreensível para fins de ações de gestão e conservação da água para seus usos múltiplos.

A análise fatorial/análise de componente principal é uma abordagem estatística que pode ser usada para analisar inter-relações entre um grande número de variáveis e explicar essas variáveis em termos de suas dimensões inerentes comuns, com o objetivo de condensar a informação contida em várias variáveis originais em um conjunto menor de variáveis estatísticas, os chamados fatores, com uma perda mínima de informação (HAIR JUNIOR et al., 2009; SANTANA, 2005).

Sendo assim, é possível analisar a estrutura dos dados e interpretá-los de forma mais clara e objetiva permitindo a análise, interpretação, e descrição dos dados em um número muito menor de conceitos quando comparado à execução de análise das variáveis originais na base de dados brutos (SANTANA, 2005).

Essa característica de redução e simplificação da informação, fez com que essas análises multivariadas de dados fossem amplamente aceitas e utilizadas em diversos estudos de avaliação da qualidade das águas, que contempla parâmetros físicos, químicos e biológicos que por vezes se relacionam entre sí (ALVES et al., 2018; BONANSEA et al., 2015; BU et al., 2014; VAREKAR et al., 2016).

Guedes et al. (2012), Araújo Neto et al. (2014), Ferreira et al. (2015), Rocha et al. (2016) e Alves et al. (2018) também utilizaram a análise multivariada aplicada ao estudo da qualidade das águas no Rio Pomba (MG), bacia metropolitana do Ceará, semiárido brasileiro, bacia do rio Sergipe e manancial de Juiz de Fora respectivamente. Todos estes trabalhos, além de monitorar a qualidade da água através de uma avaliação mais robusta e integrada dos parâmetros físicos, químicos e biológicos, buscaram refletir as características peculiares de cada região.

Dentro desta premissa surge a seguinte questão: como fornecer subsídios para a avaliação integrada dos diversos parâmetros de qualidade das águas na região amazônica, monitorados na zona portuária de Belém? Sendo assim, o presente trabalho buscou avançar para além da análise multivariada, partindo para a criação de indicadores, via análise fatorial, de forma a refletir as particularidades e a dinâmica da zona portuária de Belém, com vistas a instrumentalizar o monitoramento destas áreas, e, refletir através de indicadores as características dessas águas amazônicas.

\section{MATERIAIS E MÉTODOS}

A área de estudo, localizada na zona portuária de Belém, inserida na baia de Guajará, é formada pelo Porto de Belém, Terminal Petroquímico de Miramar e Terminal Portuário de Outeiro, que juntos formam o Porto Organizado de Belém (Figura 1).

Em termos hidrográficos, recebe contribuição hídrica e sedimentar de quatro sistemas fluviais, a saber: os rios Guamá, Moju, Acará e Capim, que despejam sedimentos lamosos na baia, tendo como rocha fonte arenitos, siltitos e argilitos da formação Barreiras (GREGÓRIO et al., 2009)

O clima da área de estudo, segundo a classificação de Köppen (KOTTEK et al., 2006), está classificado na categoria Af, sendo caracterizado por altas temperaturas e distinção de dois períodos sazonais, um 
período mais chuvoso, de dezembro a maio e outro menos chuvoso, de junho a novembro. A vegetação é caracterizada por florestas de igapó e várzea, incluindo áreas topograficamente mais baixas e floresta ombrófila densa que ocupa as áreas de terra firme ainda preservadas.

Os dados utilizados para a realização deste estudo, foram cedidos pela Companhia Docas do Pará CDP e são representados pelo conjunto de parâmetros de avaliação da qualidade da água, monitorados mensalmente no período de janeiro de 2014 a dezembro de 2015 ao longo de toda zona portuária de Belém.

O modelo estatístico foi composto por 25 parâmetros de qualidade da água, totalizando 716 amostras em 19 pontos de amostragem, conforme mostrado na figura 1.

A análise fatorial foi utilizada para resumir as informações do fenômeno estudado em um número de fatores menor do que o número total de variáveis e sem perda significativa de informação, conforme proposto por Santana et al. (2016) e Santana et al. (2017). O modelo da AF é estruturado da seguinte forma:

$$
Y_{i}=\psi_{y} F_{i}+\mu_{i}+e_{i} \quad(\mathrm{i}=1,2, \ldots, \mathrm{N})
$$

Em que ?ly é a matriz de cargas fatoriais $(p \times 1)$, Fi é o vetor de fatores latentes ( $p \times q)$ e ei é o vetor de erros aleatórios $(\mathrm{p} \times 1)$. Os Fi e ei têm variâncias iguais a: $V(V i)=\Sigma f e V(e i)=\Sigma e$, que originam a matriz de covariância de $Y i$, dada por $V(Y i)=\psi y \Sigma f \psi y+\Sigma e$ (SANTANA, 2007; SANTANA et al,. 2016). O primeiro termo do lado direito dessa equação representa a covariância dos fatores comuns e o segundo termo a covariância do erro. Assim, a parcela da variância comum presente na variável, também denominada de comunalidade,

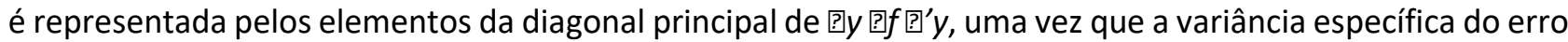
é dada pelos elementos da diagonal principal de ?e.

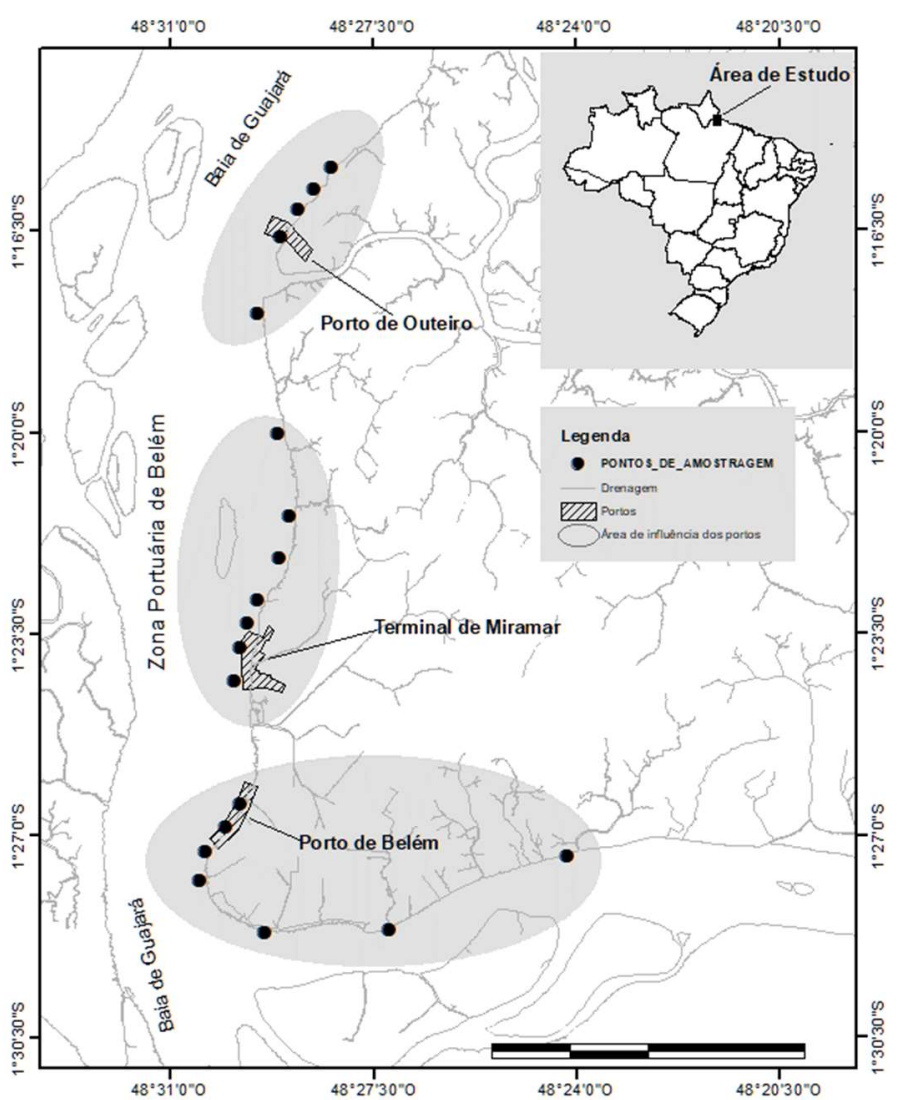

Figura 1: Carta imagem mostrando a localização da Zona Portuária de Belém 
Os erros são ortogonais aos fatores latentes, ou seja, $\operatorname{Cov}\left(e i F^{\prime} i\right)=E\left(e i F^{\prime} i\right)=0$. Assim, as inter-relações entre as p variáveis são totalmente explicadas pelos q fatores latentes. Isto significa que os vetores ei e $F i$ representam duas fontes de variação distintas e independentes. Assim, com $]_{f}=I_{q}$, o modelo reduz-se a $V(y i)$ $\left.\left.\left.=V\left(y_{i}\right)=\right]_{y}\right]^{\prime}{ }_{y}+\right]_{e}$.

A adequação da amostra à AF foi aferida pelos testes de Kaiser-Meyer-Oklin (KMO) e de Bartlett (HAIR JÚNIOR et al., 2009) com a utilização do software IBM ${ }^{\circledR}$ SPSS Statistics versão 20.0. 0 método da rotação ortogonal varimax foi utilizado porque tende a gerar um padrão mais simples e significativo para interpretar os fatores.

Os parâmetros que foram selecionadas após os testes de adequabilidade da amostra foram: alcalinidade, alumínio, cloreto, cobre, coliformes termotolerantes, condutividade elétrica, cor, demanda bioquímica de oxigênio, demanda química de oxigênio, escherichia coli, ferro, fósforo total, níquel, nitrato, nitrito, nitrogênio amoniacal, oxigênio dissolvido, potencial hidrogeniônico, salinidade, sódio, sólidos totais dissolvidos, sólidos totais sedimentáveis, sulfato, temperatura, turbidez.

Para a criação de indicadores e posteriormente do Indicador de Avaliação Padronizado - IAP para cada porto, foram considerados os resultados gerados a partir da aplicação da AF: Raíz Latente do Fator (RLf); fator gerado a partir do teste de Bartlett, paralelo à matriz de dados brutos, com números de fatores equivalentes ao número de fatores gerados após aplicação da AF (F1, F2...Fi). A partir disso criou-se o Lambda $(\lambda)$, o qual deu suporte ao prosseguimento da análise, conforme expressão abaixo:

$$
\lambda=\frac{R L f i}{\sum R L} \quad \text { Equação } 1
$$

Dessa forma, para cada fator gerado na $A F$, foi gerado um $\lambda,(\lambda 1, \lambda 2, \ldots . \lambda i)$ o qual foi utilizado na formação dos indicadores (I). Conforme expressão a seguir.

$$
I=(\lambda 1 . F 1)+(\lambda 2 . F 2)+(\lambda i . F i)
$$

Equação 2

Posteriormente se deu a padronização dos indicadores, os quais são equivalentes ao número total de amostras por parâmetro $(11,12, \ldots . . . \mathrm{li})$, transformando-os no IAP, Indicador de Avaliação Padronizado de 0 a 100, a partir do menor e maior valor do indicador Imin e Imax respectivamente, gerado através da equação 3:

$$
I A P=\frac{I i-\operatorname{Imin}}{(\operatorname{Imax}-\operatorname{Imin})} \times 100 \quad \text { Equação } 3
$$

A partir da padronização dos indicadores gerados, foi possível estabelecer as faixas de avaliação da qualidade da água ponderadas de acordo com as faixas do índice de qualidade da água estabelecido pela CETESB (2016). Os indicadores padronizados variaram de 0 a 100, e para este trabalho as faixas de avaliação da qualidade da água, foram: péssima $(I A P \leq 19)$, ruim $(19<\mid A P \leq 36)$, regular $(36<\mid A P \leq 51)$, boa $(51<\mid A P \leq 79)$ e ótima $(79<\mathrm{IAP} \leq 100)$.

Neste trabalho foram gerados indicadores de avaliação padronizado (IAP) para a qualidade da água dos Porto de Belém, Terminal Petroquímico de Miramar e Terminal Portuário de Outeiro com intuito de comparar a qualidade das águas entre os três portos. 


\section{RESULTADOS E DISCUSSÃO}

Os resultados da análise fatorial (AF) estão expressos na tabela 1. A amostragem dos parâmetros de qualidade da água mostrou-se passível a aplicação da AF; a matriz de correlação apresentou determinante diferente de zero, admitindo a matriz inversa, portanto a solução além de única tende a ser a que melhor representa o fenômeno estudado, nesse caso a qualidade da água na zona portuária.

Quanto à adequação da amostra, o teste KMO foi de 0,77 , superior ao limite aceitável de 0,5 , e o teste de esfericidade de Bartlett foi significativo a 1\% de probabilidade. Ao total foram extraídos nove fatores que explicaram $75,33 \%$ da variância total dos dados.

O primeiro fator explicou $21,29 \%$ da variância comum e foi representado pelo efeito dos parâmetros: Sólidos Totais Dissolvidos - STD, condutividade elétrica, salinidade, sulfato, sódio e cloreto, que refletiu as características do estuário como zona de transição fluviomarinha com influência da maré e intrusão salina (GREGÓRIO et al., 2009).

O segundo fator explicou 8,78\% da variância e captou o efeito dos parâmetros cor, ferro, alcalinidade e nitrogênio amoniacal. Em ambientes com abundância de compostos orgânicos, representados por ácidos húmicos e fúlvicos, bem como ambientes que recebem descargas de efluentes domésticos e industriais, predominam a presença de bactérias que mineralizam esses compostos, liberando o nitrogênio amoniacal e o ferro complexado (LOPES et al., 2017).

Tabela 1: Matriz de cargas fatoriais do modelo de avaliação da qualidade da água na Zona Portuária de Belém.

\begin{tabular}{|c|c|c|c|c|c|c|c|c|c|c|}
\hline \multirow{2}{*}{ PARÂMETROS } & \multicolumn{9}{|c|}{ FATORES COMUNS } & \multirow{2}{*}{ COMUNALIDADE } \\
\hline & 1 & 2 & 3 & 4 & 5 & 6 & 7 & 8 & 9 & \\
\hline STD & 0.958 & 0.122 & -0.06 & -0.034 & -0.125 & -0.014 & 0.024 & -0.018 & -0.06 & 0.660 \\
\hline Condutividade & 0.943 & 0.133 & -0.043 & -0.036 & -0.145 & -0.016 & -0.014 & -0.026 & -0.064 & 0.584 \\
\hline Salinidade & 0.928 & 0.15 & -0.024 & -0.045 & -0.151 & -0.018 & -0.031 & -0.043 & -0.063 & 0.936 \\
\hline Sulfato & 0.903 & 0.121 & -0.072 & -0.048 & -0.104 & -0.008 & 0.11 & -0.01 & -0.089 & 0.957 \\
\hline Sódio & 0.785 & 0.293 & -0.153 & -0.046 & -0.133 & -0.014 & 0.118 & -0.073 & 0.25 & 0.801 \\
\hline Cloreto & 0.702 & -0.051 & -0.197 & 0.006 & 0.117 & 0.023 & 0.308 & 0.076 & -0.016 & 0.749 \\
\hline Cor verdadeira & -0.277 & -0.733 & 0.241 & 0.021 & -0.013 & -0.029 & -0.094 & -0.102 & 0.017 & 0.796 \\
\hline Ferro & -0.432 & -0.654 & 0.006 & 0.01 & 0.037 & -0.027 & -0.06 & -0.018 & 0.075 & 0.693 \\
\hline Alcalinidade & 0.277 & 0.614 & -0.025 & -0.019 & -0.401 & 0.002 & 0.086 & -0.185 & -0.079 & 0.664 \\
\hline N-Amoniacal & -0.171 & 0.492 & 0.388 & 0.274 & -0.067 & -0.023 & -0.177 & -0.209 & 0.026 & 0.650 \\
\hline DQO & -0.148 & -0.154 & 0.801 & -0.002 & 0.168 & -0.004 & -0.068 & 0.015 & -0.052 & 0.636 \\
\hline $\mathrm{DBO}$ & -0.105 & -0.002 & 0.758 & 0.044 & 0.123 & -0.007 & 0.125 & 0.098 & 0.007 & 0.656 \\
\hline Temperatura & -0.035 & 0.451 & 0.473 & 0.01 & 0.082 & 0.047 & -0.043 & 0.236 & -0.297 & 0.868 \\
\hline Colif. Termoto. & -0.05 & 0.032 & 0.022 & 0.938 & -0.043 & -0.007 & -0.043 & 0.052 & 0.001 & 0.428 \\
\hline E. coli & -0.055 & -0.009 & 0.03 & 0.935 & 0.005 & -0.014 & -0.018 & 0.091 & -0.036 & 0.578 \\
\hline STS & -0.202 & 0.057 & 0.27 & -0.036 & 0.807 & 0.034 & 0.005 & -0.121 & 0.109 & 0.628 \\
\hline Turbidez & -0.339 & -0.102 & 0.222 & -0.027 & 0.739 & -0.017 & -0.092 & -0.092 & -0.101 & 0.724 \\
\hline Fósforo & -0.078 & 0.231 & 0.342 & -0.005 & -0.477 & -0.04 & 0.024 & -0.12 & -0.084 & 0.917 \\
\hline Níquel & -0.004 & -0.002 & 0.005 & -0.003 & -0.015 & 0.952 & -0.009 & -0.013 & -0.051 & 0.859 \\
\hline Cobre & -0.023 & 0.042 & -0.038 & -0.018 & 0.051 & 0.942 & -0.101 & 0.004 & 0.068 & 0.627 \\
\hline OD & 0.073 & -0.037 & 0.025 & -0.068 & -0.021 & -0.111 & 0.863 & -0.127 & -0.123 & 0.909 \\
\hline $\mathrm{Ph}$ & 0.35 & 0.36 & 0.09 & 0.002 & -0.135 & -0.002 & 0.604 & 0.067 & 0.109 & 0.909 \\
\hline Nitrito & 0.057 & 0.075 & -0.034 & 0.054 & 0.075 & -0.047 & -0.089 & 0.757 & -0.185 & 0.827 \\
\hline Nitrato & -0.151 & -0.105 & 0.076 & 0.105 & -0.218 & 0.046 & 0.012 & 0.703 & 0.247 & 0.891 \\
\hline Alumínio & -0.079 & -0.097 & -0.009 & -0.034 & 0.083 & 0.014 & -0.074 & -0.002 & 0.911 & 0.888 \\
\hline RAÍZ LATENTE & 5.324 & 2.197 & 1.981 & 1.863 & 1.826 & 1.82 & 1.341 & 1.305 & 1.177 & 14.663 \\
\hline \%VARIÂNCIA & 21.29 & 8.788 & 7.925 & 7.451 & 7.304 & 7.281 & 5.366 & 5.22 & 4.707 & 75.339 \\
\hline MAA & \multicolumn{10}{|c|}{ KMO: 0,77; Teste de Bartlett: 13.642,939 $(p<0,01)$} \\
\hline
\end{tabular}

Quando a matéria orgânica é metabolizada, o $\mathrm{Fe}^{2+}$ é liberado ao ambiente aquático, rapidamente 
oxidado e precipitado na forma de óxidos de ferro, reduzindo assim sua concentração na coluna d'água (ESTEVES et al., 2011).

Toda essa dinâmica de mineralização dos compostos orgânicos, aumenta a penetração de luz, reduzindo quantitativamente os valores para medição do parâmetro cor. Com efeito a presença de nitrogênio amoniacal pode provocar um efeito tampão, mantendo as condições de alcalinidade características do ambiente estuarino, justificando o comportamento do parâmetro no fator. De acordo com Gregório et al. (2009), altos teores de matéria orgânica encontrados na área de estudo, estão relacionados ao lançamento de esgoto doméstico e industrial descartados in natura no corpo hídrico.

A degradabilidade de compostos químicos foi expressa no terceiro fator e explicou $1,98 \%$ da variância, representado pelos parâmetros Demanda Química de Oxigênio, Demanda Bioquímica de Oxigênio e temperatura. Esse fator representou a influência das entradas de matéria orgânica no corpo d'água, bem como de outros elementos químicos oriundo da própria atividade portuária que irão variar sua concentração no corpo d'água de acordo com as variações de temperatura que irá influenciar na velocidade de metabolização dos compostos (LOPES et al., 2017).

O quarto fator caracterizado pela componente patogênica na avaliação da qualidade das águas foi representado pelos coliformes termotolerantes juntamente com as bactérias Escherechia Coli, ambos indicadores de contaminação do recurso hídrico, sobretudo com efeitos a saúde humana.

Estudos de Maranhão (2011), apontam altos teores de coliformes em virtude da ocupação desordenada ao longo da microbacia de Val-de-cães, um dos principais contribuintes da Baia do Guajará. Miranda et al. (2015) ao avaliar a qualidade das águas na ilha de mosqueiro, a qual faz parte do estuário Guajarino, registrou a presença de coliformes termotolerantes e os relacionou ao lançamento de esgoto doméstico.

O quinto fator agrupou os parâmetros sólidos totais sedimentáveis, turbidez e fósforo. A presença de óxidos e hidróxidos de ferro já encontrados no corpo hídrico e descritos no fator 2, podem absorver espécies fosfatadas precipitando essa forma de fósforo no sedimento e consequentemente retirando-o da coluna d'água (ESTEVES, 2011). Por outro lado, o aumento de sólidos totais sedimentáveis é um indicativo de entrada de sólidos totais no sistema que irão influenciar na turbidez da água, sobretudo a fração de sólidos em suspensão.

O sexto fator foi composto pelos metais pesados Cobre e Níquel e refletiu a atividade industrial ao longo da margem direita da Baia, representada por indústrias de galvanoplastia, curtumes, beneficiamento do pescado, madeireiras, além da intensa atividade portuária (GREGÓRIO et al., 2009). Santos et al. (2012), destacam em seu estudo que os sedimentos de fundo da margem direita da baia de Guajará apresentam-se sobre influência de efluentes domésticos e industriais, fato também destacado no estudo de Oliveira et al., 2015 que também avaliou os sedimentos de fundo da baía de Guajará.

De acordo com Oliveira et al. (2017), a zona portuária de vila do conde, pertencente ao estuário do Marajoara, contíguo ao Guajarino, apresenta valores elevados de metais pesados e hidrocarbonetos. A presença destes contaminantes, segundo os autores, está relacionada a atividade portuária naquela região. 
Outras fontes destes metais para o ambiente aquático são o lançamento de efluentes domésticos, fabricação e descarte de pilhas e baterias, pigmentos de tintas, entre outros (OLIVEIRA et al., 2018; MASON, 2013).

Os parâmetros oxigênio dissolvido (OD) e potencial hidrogeniônico $(\mathrm{pH})$, formaram o sétimo fator. Este agrupamento se dá pelo fato da redução de OD estar intimamente ligada ao aumento da acidez nas águas, com diminuição do $\mathrm{pH}$, por conta da mineralização de material orgânico recente que entra no sistema hídrico, principalmente através de efluentes não tratados (GREGÓRIO et al., 2009)

O oitavo fator, representado pelos parâmetros nitrito e nitrato evidenciou as formas oxidadas de nitrogênio no ambiente aquático que potencialmente indicam a presença de poluentes na área de estudo, provenientes de lançamentos de efluentes. Santos et al. (2014), em seu estudo na baia do Guajará, relacionou as concentrações de nitrito à lançamentos de efluentes na área. Maranhão (2011) relacionou o aumento das concentrações de nitrito ao lançamento de efluentes de origem industrial, o que colabora para um baixo teor de oxigênio dissolvido no local. Com efeito, Moura (2007) aponta inúmeras fontes de lançamento de efluentes domésticos e industriais ao longo da zona portuária de Belém, comprometendo a qualidade das águas superficiais por influenciarem no aumento da concentração de nutrientes como o nitrogênio e consequentemente, no processo de eutrofização.

Por fim o nono fator formado, é composto por apenas um parâmetro, o Alumínio. Embora ele esteja sozinho no fator, a variância explicada do mesmo é comparada à variância de fatores que possuem mais de um parâmetro na sua formação.

A presença de Alumínio em águas superficiais pode estar relacionada a fontes geológicas deste elemento através de escoamento superficial, que carreia material sedimentar contendo aluminosilicatos, principalmente esmectita e ilita (SANTOS et al., 2012; PEREIRA et al., 2018), oriundo das margens da baia e ilhas adjacentes (OLIVEIRA et al., 2015). Outra fonte pode estar relacionada a descarga de sedimentos trazidos pelos diversos rios que compõem a baia, como o rio Guamá, Mojú e Acará, que podem conduzir também minerais aluminosos (OLIVEIRA et al., 2015; SINGH et al., 2019).

\section{Indicador de avaliação padronizado (IAP)}

A Tabela 2 ilustra a classificação da qualidade da água para os portos de Belém, Terminal Petroquímico de Miramar e Porto de Outeiro. Os resultados são a média de amostras que se enquadraram em cada faixa do indicador.

Para o porto de Belém, 46,03\% das amostras analisadas ficaram na faixa considerada de qualidade péssima pelo IAP, 42,85\% das amostras encontram-se na faixa de ruim, 7,53\% das amostras indicam qualidade regular, 3,17\% encontram-se na faixa boa e somente $0,39 \%$ do total de amostras observadas ficaram na faixa ótima.

De maneira semelhante o Terminal Petroquímico de Miramar concentrou as amostras nas faixas de IAP péssima (46,98\%) e ruim (45,68\%). Na faixa de IAP regular, estiveram 7,32\% do total de amostras, por outro lado, nenhuma das amostras apresentou IAP nas faixas boa e ótima.

Por outro lado, a área do porto de Outeiro concentrou mais amostras nas faixas regular $(9,93 \%)$ e 
boa $(9,93 \%)$, todavia o quantitativo de as amostras que se enquadraram na faixa de péssima qualidade foi maior (52,58\%), em relação aos portos de Belém e Miramar.

De um modo geral, o Indicador de Avaliação Padronizado para qualidade da água da zona portuária de Belém refletiu a influência das atividades antrópicas estabelecidas ao longo dos anos na margem direita da baia de Guajará, notadamente a entrada de efluentes domésticos e indústrias in natura. Porém, não se pode descartar que a atividade portuária desenvolvida na área de estudo, não possa contribuir como vetor de contaminantes para o sistema hídrico do local. O movimento de cargas e combustíveis, podem, se lançados no sistema hídrico, contribuir para uma perda na qualidade do mesmo (OLIVEIRA et al., 2017).

Tabela 2: Faixas do Indicador de Avaliação Padronizado (IAP) para zona portuária de Belém.

\begin{tabular}{|c|c|c|c|c|c|c|}
\hline \multirow{2}{*}{ Faixas IAP } & \multicolumn{2}{|l|}{ Porto de Belém } & \multicolumn{2}{|c|}{ Terminal Petroquímico de Miramar } & \multicolumn{2}{|l|}{ Porto de Outeiro } \\
\hline & № de amostras & Valor médio IAP & № de amostras & Valor médio IAP & № de amostras & Valor médio IAP \\
\hline Ótima $(79 \leq \mathrm{IAP} \leq 100)$ & 1 & 100 & 0 & 0,00 & 1 & 79,67 \\
\hline Boa $(51 \leq$ IAP $\leq 79)$ & 8 & 58,73 & 0 & 0,00 & 23 & 59,89 \\
\hline Regular $(36 \leq \mathrm{IAP} \leq 51)$ & 19 & 39,18 & 17 & 39,38 & 23 & 43,06 \\
\hline Ruim $(19 \leq \mathrm{IAP} \leq 36)$ & 108 & 25,97 & 106 & 24,72 & 63 & 24,11 \\
\hline Péssima (IAP $\leq 19)$ & 116 & 11,95 & 109 & 13,29 & 122 & 10,29 \\
\hline Total de amostras & 252 & & 232 & & 232 & \\
\hline
\end{tabular}

\section{CONCLUSÕES}

A análise fatorial permitiu elencar fatores que se mostraram condizentes conceitualmente, apontando uma adequada aplicação do método, tendo alto poder de explicação para a dinâmica da qualidade da água na área de estudo, agrupando os parâmetros de forma mais significativa para indicar as modificações que tem ocorrido e suas possíveis fontes.

A visão integrada da análise multivariada em dados ambientais foi fundamental para evidenciar quais parâmetros tem mais poder de explicação para a Zona Portuária de Belém, notadamente os parâmetros destacados como representando a dinâmica do estuário no qual está inserida a área de estudo.

Por fim a criação de indicadores padronizados deu uma visão geral da qualidade da água para toda zona portuária, mostrando os efeitos das diversas atividades desenvolvidas e classificando suas águas com qualidade péssima e ruim. Notadamente, essa qualidade tem sido comprometida pela atividade portuária que envolve o transporte, estocagem e armazenamento de cargas e combustíveis, além da descarga de esgotos in natura recebidos por esse corpo d'água, advindos da cidade de Belém juntamente com os efluentes das indústrias de galvanoplastia, beneficiamento do pescado, curtumes e madeireiras das adjacências.

\section{REFERÊNCIAS}

ALVES, J. P. H.; FONSECA, L. C.; CHIELLE, R. S.; MACEDO, L. C. B.. Monitoring water quality of the Sergipe River basin: an evaluation using multivariate data analysis. Revista Brasileira de Recursos Hídricos, v.23, n.e27, 2018. DOI: https://doi.org/10.1590/2318-0331.23182017012

ARAÚJO NETO, J. R.; SALES, M. M.; PALACIO, H. A. Q.; BRASIL, J. B.. Seleção dos indicadores da salinidade das águas superficiais da bacia Metropolitana do Ceará pelo emprego da análise multivariada. Water Resources and
Irrigation Management, v.3, n.2, p.37-46, 2014. DOI: http://doi.org/10.19149/2316-6886/wrim.v3n2p37-46

BONANSEA, M.; LEDESMA, C.; RODRIGUEZ, C.; PINOTTI, L.. Water quality assessment using multivariate statistical techniques in Rio Tercero Reservoir, Argentina. Hydrology Research, v.46, n.3, p.377-388, 2015. DOI: http://dx.doi.org/10.2166/nh.2014.174

BU, H.; MENG, W.; ZHANG, Y.. Spatial and seasonal 
characteristics of river water chemistry in the Taizi River in Northeast China. Environmental Monitoring and Assessment, v.186, n.6, p.3619-3632, 2014. DOI: http://dx.doi.org/10.1007/s10661-014-36446.PMid:24477615

CASTRO, E.. Cidades amazônicas na confluência das águas. In: UHLY, S; SOUZA, E. L.. A questão da água na grande Belém. Belém: Casa de estudos germânicos, 2004. p.13-37.

CETESB. Companhia Ambiental do Estado de São Paulo. Apêndice $D$, Índices de qualidade das águas (1). São Paulo: CETESB, 2016.

CORREIA, K. A.; LUCZYNSKY, E.; MENDES, A. C. MIRANDA, A. G. O.; SILVA, M. W. C.; CUNHA, I. R. V.. A utilização do Ground Penetrating Radar (GPR) na definição de penetração de cunha salina e no monitoramento do nível freático em praia estuarina amazônica. Revista Águas Subterrâneas, v.33, n.1, p.87-101, 2019.

DOI: http://dx.doi.org/10.14295/ras.v33i1.29095

ESTEVES, F. A.. Fundamentos de Limnologia. Rio de Janeiro: Interciência, 2011.

FERREIRA, K. C. D.; LOPES, F. B.; ANDRADE, E. M.; MEIRELES, A. C. M.; SILVA, G. S.. Adaptação do índice de qualidade de água da National Sanitation Foundation ao semiárido brasileiro. Revista de Ciência Agronômica, v.46, n.2, p.277286, 2015

GREGÓRIO, A. M. S.; MENDES, A. C.. Batimetria e sedimentologia da baia do Guajará, Belém, Estado do Pará, Brasil. Amazônia: Ci \& Desenv., Belém, v.5, n.9, 2009.

GUEDES, H. S.; SILVA, D. D.; ELESTON, A. A. A.; RIBEIRO, C. B. M.; MATOS, A. T.; SOARES, J. H. P.. Aplicação da análise estatística multivariada no estudo da qualidade da água do Rio Pomba, MG. R. Bras. de Eng. Agric. Ambiental, v.16, n.5, p.558-563, 2012.

HAIR JÚNIOR, J. F.; BLACK, W. C.; BABIN, B. J.; ANDERSON, R. E.; TATHAM, R. L.. Análise multivariada de dados. Porto Alegre: Bookman, 2009.

LOPES, Y. K. L.; NEU, V.; FELIZZOLA, J. F.; TEIXEIRA, L. C. G. M.; COSTA, C. E. A. S.. Variabilidade hidrodinâmica em aguas do estuário amazônico. Ambiência Guarapuava, v.13, n.2, p.325-341, 2017. DOI: http://doi.org/10.5935/ambiência.2017.02.05

KOTTEK, M.; GRIESER, J.; BECK, C.; RUDOLF, B.; RUBEL, F. World map of the Köppen-Geiger climate classification updated. Meteorologische Zeitschrift, v.15, n.3, p.259-263, 2006. DOI: http://doi.org/10.1127/0941-2948/2006/0130

MARANHÃO, R. A.. Impactos da ocupação urbana e qualidade das águas superficiais na microbacia de Val-decães (Belém/PA). Caminhos de Geografia, Uberlândia, v.12, n.38, p.176-186, 2011.

MASON, R. P.. Trace metals in aquactic systems. Oxford: Wiley-Blackwell, 2013. DOI: http://doi.org/10.1002/9781118274576

MIRANDA, M. V. T.; SANTOS, M. L. S.; PEREIRA, J. A. R.; MESQUITA, K. F. C.. Índice de qualidade da água da ilha de
Mosqueiro-PA. Revista DAE, n.201, p.74-81, 2015. DOI: http://doi.org/10.4322/dae.2015.005

MOURA, E. M.. Mapeamento do halo de dispersão formado por efluentes industriais lançados na baia do Guajará no trecho compreendido entre o bairro de Val-de-cães e o distrito de Icoarací. Dissertação (Mestrado em Geologia e Geoquímica) - Universidade Federal do Pará, Belém, 2007

OLIVEIRA, E. C.; LAFON, J. M.; CORREA, J. A. M.; CARVALHO, J. H. S.; DIAS, F. F.; TADDEI, M. H. T.. Distribuição dos metais traços em sedimentos de fundo do sistema hidrográfico da região de Belém, PA (margem oeste da baía do Guajará e rio Carnapijó). Geochimica Brasiliensis, v.29, n.2 p139-153, 2015.

OLIVEIRA, E. S.; OLIVEIRA, G. M. T. S.; MELO, N. F. A. M. Concentração de hidrocarbonetos alifáticos e metais pesados na zona portuária de Vila do Conde, Rio Pará Brasil. Espacios, v.38, n.39, p.25, 2017.

OLIVEIRA, E. S.; OLIVEIRA, G. M. T. S.; MELO, N. F. A. M. Metais pesados no ambiente aquático. In: SOUZA, R. A. L. Ecossistemas aquáticos: tópicos especiais. Belém: Edufra, 2018.

PEREIRA, C. A. F.; MAIA, L. F. O.; FARIA, M. C. S.; FIDÊNCIO, P. H.; BOMFETI, C. A.; BARBOSA JUNIOR, F.; RODRIGUES, J. L.. Seasonal variations, metal distribution and water quality in the Todos os Santos River, Southeastern Brazil: a multivariate analysis. An Acad. Bras. Cienc., v.90, n.3, p.2701-2710, 2018. DOI: http://dx.doi.org/10.1590/00013765201820170420

RAMOS, J.. Poluição e contaminação da orla de Belém, PA In: UHLY, S; SOUZA, E. L.. A questão da água na grande Belém. Belém: Casa de estudos germânicos, 2004. p.121148.

ROCHA, C. H. B.; PEREIRA, A. M.. Análise multivariada para seleção de parâmetros de monitoramento em manancial de Juiz de Fora, Minas Gerais. Rev. Ambient. Água, Taubaté, v.11, n.1, 2016. DOI: http://doi.org/10.4136/ambiagua.1590

SANTANA, A. C.. Elementos de economia, agronegócio e desenvolvimento local. Belém: UFRA, 2005.

SANTANA, A. C.; SALOMÃO, R. P.; SANTANA, A. L.; CASTILHO, A. F.. O valor econômico total da área de savana metalófita, ou "canga", da Floresta Nacional de Carajás, estado do Pará: uma contribuição teórica e metodológica da avaliação contingente. Papers do NAEA, Belém, v.23, n.48, p.1-48, 2016.

SANTANA, A. C.; SANTANA, A. L.; AMIN, M. M.; SALOMÃO, R. P.; COSTA, N. L.; SANTOS, M. A. S.; CASTILHO, A.. Theoretical and methodological contributions to the contingent evaluation of the natural resources of the Carajás national forest. International Journal of Development Research, v.7, n.4, p.12468-12474, 2017.

SANTANA, A. C.. Índice de desempenho competitivo das empresas de polpa de frutas do Estado do Pará. Revista de Economia e Sociologia Rural, v.45, n.4, p.749-775, 2007.

SANTOS, M. L. S.; HOLANDA, P.; PEREIRA, I.; RODRIGUES, S.; 
PEREIRA, J. A. R.; MESQUITA, K.. Influência das condições da maré na qualidade de água do rio Guamá e baia de Guajará. Bol. Tec. Cient. Cepmor, v.14, n.1, p.17-25, 2014.

SANTOS, S. N.; LAFON, J. M.; CORREA, J. A. M.. Distribuição isotópica de $\mathrm{Pb}$ em sedimentos de fundo da foz do rio Guamá e da baia de Guajará. Química Nova, v.35, n.2, p.249-256, 2012.

TUNDISI, J. G.; MATSUMURA-TUNDISI, T.. Liminologia. São Paulo: Oficina de Texto, 2013
SINGH, N. D.; CHINNI, V.; SINGH, S. K.. Dissolved aluminium cycling in the northern, equatorial and subtropical gyre region of the Indian Ocean. Geochimica et Cosmochimica Acta, v.268, p160-185,2019. DOI: http://doi.org/10.1016/i.gca.2019.09.028

VAREKAR, V.; KARMAKAR, S.; JHA, R.. Seasonal rationalization of river water quality sampling locations: a comparative study of the modified Sanders and multivariate statistical approaches. Environmental Science and Pollution Research International, v.23, n.3, p.2308-2328, 2016. DOI: http://dx.doi.org/10.1007/s11356-015-5349-y

A CBPC - Companhia Brasileira de Produção Científica (CNPJ: 11.221.422/0001-03) detém os direitos materiais desta publicação. Os direitos referem-se à publicação do trabalho em qualquer parte do mundo, incluindo os direitos às renovações, expansões e disseminações da contribuição, bem como outros direitos subsidiários. Todos os trabalhos publicados eletronicamente poderão posteriormente ser publicados em coletâneas impressas sob coordenação da Sustenere Publishing, da Companhia Brasileira de Produção Científica e seus parceiros autorizados. Os (as) autores (as) preservam os direitos autorais, mas não têm permissão para a publicação da contribuição em outro meio, impresso ou digital, em português ou em tradução. 